\title{
Hepatitis B virus infection in multitransfused haemophiliacs
}

\author{
G NEBBIA, G A MORONI, L SIMONI, M BELLI, AND V CARNELLI \\ Pediatric Department of the University of Milan and Blood Transfusion Center, Instituti Clinici di \\ Perfezionamento, Milan, Italy
}

SUMmary A longitudinal study of 44 haemophilic children, all in a treatment programme with factor concentrates, was undertaken to evaluate the occurrence, characteristics, and evolution of hepatitis B virus (HBV) infection. Twenty four children (55\%) (group I) showed signs of HBV infection, while 20 (45\%) (group II) did not. Age at onset of treatment, number of infusions, and total amount of concentrate received did not show significant differences between the two groups. In group I only four children $(16 \%)$ had symptomatic acute hepatitis. Chronic liver disease was present in nine patients (38\% of infected children). The early age of infection would seem to be an important factor for predicting chronic evolution. Evidence of $\delta$ infection in three children with severe liver disease seemed to confirm the high pathogenicity of this agent. Because of the risks associated with chronic $\mathrm{HBV}$ infection a careful follow up of patients positive for hepatitis B surface antigen is mandatory.

$$
\begin{aligned}
& \text { Key for abbreviations used in text } \\
& \text { HBV: Hepatitis B virus. } \\
& \text { HBsAg: Hepatitis B surface antigen. } \\
& \text { HBeAg: Hepatitis B e antigen. } \\
& \text { Anti-HBs: Antibody to } \mathrm{HBsAg} \\
& \text { Anti-HBc: Antibody to } \mathrm{HBcAg} \text {. } \\
& \text { Anti-HBe: Antibody to } \mathrm{HBeAg} \text {. }
\end{aligned}
$$

Post-transfusion hepatitis is a well known complication of treatment with blood derivatives in patients with coagulation disorders, ${ }^{1-3}$ and hepatitis $B$ virus (HBV) infection, with a possible associated liver disease, has often been investigated in such patients. $^{2} 45$

According to previous reports ${ }^{3-5}$ about $90 \%$ of haemophilic patients show signs of HBV infection during replacement therapy, and a history of symptomatic acute hepatitis is rarely present; in a small number there is an evolution to chronicity, with liver disease ranging from chronic persistent hepatitis to active cirrhosis. ${ }^{6-9}$ Up to now this subject has been rarely studied in haemophilic children, ${ }^{9}{ }^{10}$ even though this group offers an excellent opportunity for a thorough analysis, including the amount of exposure to clotting concentrates before infection, the age at which infection occurs, the possibility of developing chronic hepatitis B surface antigenaemia and chronic liver disease, seroconversion (how many and after how long), and the eventual superinfection with $\delta$ agent. In short, children offer a unique group for assessing the natural course and long term evolution of HBV infection. Therefore, we have undertaken a longitudinal study of 44 haemophilic children, all in a treatment programme with commercial factor concentrates, to evaluate the occurrence, characteristics, and evolution of $\mathrm{HBV}$ infection.

\section{Patients and methods}

Forty four children (36 with haemophilia A, four with haemophilia B, and four with von Willebrand's disease) have been followed and tested at three to six month intervals since 1979 for hepatitis B surface ( $\mathrm{HBsAg})$ and $\mathrm{e}(\mathrm{HBeAg})$ antigens and surface (anti- HBs), core (anti-HBc) and e (anti-HBe) antibodies by radioimmunoassay using commercial kits (Abbott, Chicago, Illinois, United States). The children were all either on replacement therapy with commercial factor VIII and IX concentrates of both European and North American origin or were about to start it at the beginning of the study. This type of treatment is widely used by paediatric haematologists in Italy as the trend is to develop the greatest psychological and physical independence in children by home treatment, and factor concentrates seem 
more suitable than cryoprecipitates for this purpose. In 1979,29 children were already in care at our centre, and since then 15 others have been added to the follow up programme. All the children have been followed for at least one year after starting treatment. The mean age (range) at the time of initial treatment was 31 months ( 1 month to 10 years 9 months) in the 43 children where accurate documentation was available.

The mean age of the children at present is 9 years 7 months (range 2.5 to 19 years). A child was considered infected when $\mathrm{HBsAg}$, together with other related signs, was found or when there was repeated presence of $\mathrm{HBV}$ antibodies. The isolated presence of anti-HBs or anti-HBc, or both, which was not found again during further testing, was considered the result of passive transmission by replacement therapy. The patients were assigned to two groups (group I and II) according to the respective presence or absence of $\mathrm{HBV}$ infection throughout the follow up. All the cases with $\mathrm{HBsAg}$ were followed until the antigen disappeared or, if the chronic carrier state developed, were kept under observation to the present time.

All the children negative for HBV signs were vaccinated against $\mathrm{HBV}$. Along with the signs, routine clinical examination and liver function tests (bilirubin concentration, prothrombin time, protein electrophoresis, and alanine aminotransferase, aspartate aminotransferase, and alkaline phosphatase activities) were performed at regular intervals in all the patients. Careful record of clinically relevant events, of the age at the start of treatment, and of amounts of concentrate given to each patient were kept. In chronic carriers of $\mathrm{HBsAg}$,

Table 1 Serological signs of hepatitis $B$ virus infection during follow up

\begin{tabular}{lccc}
\hline & \multicolumn{2}{l}{ Year of follow up } \\
\cline { 2 - 4 } & 1979 & 1982 & 1984 \\
\hline $\mathrm{n}$ & 29 & 36 & 44 \\
HBsAg positive & 12 & 7 & 9 \\
Antibodies to HBV & 8 & 14 & 15 \\
No HBV signs & 9 & 15 & 20 \\
\hline
\end{tabular}

serum $\delta$ antigen and antibody concentrations were tested by a previously described solid phase radioimmunoassay. ${ }^{11}$ Moreover, when chronic HBV infection had been present for at least five years a determination of $\alpha$ fetoprotein and abdominal ultrasound examination were performed every six months.

Liver biopsy examinations. All the patients with chronic liver disease and chronic HBV infection were considered eligible for liver biopsy examination, but it was performed in only two patients, owing to the reluctance of the other parents. The procedure was performed under substitution therapy with commercial factor VIII concentrate, as previously described, ${ }^{7}$ by a Menghini needle. The specimens underwent routine histologic evaluation, according to international criteria, ${ }^{12}$ and one portion was tested for $\delta$ antigen by immunofluorescence.

Statistical analysis. Data were routinely analysed, and the non-parametric Mann Whitney $U$ test was applied.

\section{Results}

Details about the evolution of serological signs of HBV infection throughout the follow up are presented in Table 1 . As a whole, 24 children $(55 \%)$ (group I) developed infection, while 20 (group II) did not. The main characteristics of treatment in the two groups are summarised in Table 2. None of the variables examined (age at onset of treatment, number of infusions given, and total amount of concentrate received) showed significant differences between children with and without infection $(p>0.05)$.

HBV infection (onset and evolution). In group I the mean age of infection with $\mathrm{HBV}$ was 5 years 4 months (range 2 years 3 months to 12 years 2 months). In 16 children the infection was detected by the presence of $\mathrm{HBsAg}$. In six cases it was already present at the beginning of the study (with a history of acute hepatitis in three patients). In six patients the infection occurred during the first year,

Table 2 Characteristics of treatment with factor concentrate

\begin{tabular}{|c|c|c|c|c|c|c|c|c|}
\hline & \multirow[b]{2}{*}{$n=$} & \multicolumn{2}{|c|}{$\begin{array}{l}\text { Age at onset } \\
\text { of treatment (months) }\end{array}$} & \multicolumn{3}{|c|}{ No of infusions* } & \multicolumn{2}{|c|}{$\begin{array}{l}\text { Total amount of } \\
\text { concentrate (IU) }\end{array}$} \\
\hline & & Range & Mean & Range & Mean (SE) & Median & Mean (SE) & Median \\
\hline Group 1 & $24 \because$ & $1-129$ & 28 & $1-220$ & $56(12)$ & 31 & $29711(10112)$ & 9875 \\
\hline Group 2 & 20 & $1-107$ & 35 & $1-262$ & 41 (14) & 12 & $22003 \quad(8564)$ & 4015 \\
\hline
\end{tabular}

${ }^{*}$ For group 1 treatment was considered until the occurrence of $\mathrm{HBV}$ infection; for group 2 it was considered until anti-HBV vaccination. 
582 Nebbia, Moroni, Simoni, Belli, and Carnelli

Table 3 Details of chronic hepatitis $B$ virus in nine haemophilic children

\begin{tabular}{|c|c|c|c|c|c|c|c|}
\hline \multirow[t]{2}{*}{ Case No } & \multirow{2}{*}{$\begin{array}{l}\text { Age at } \\
\text { infection } \\
\text { (years) }\end{array}$} & \multirow{2}{*}{$\begin{array}{l}\text { Duration of } \\
\text { HBsAg* } \\
\text { positivity } \\
\text { (years) }\end{array}$} & \multicolumn{3}{|c|}{ Positive or negative for } & \multirow{2}{*}{$\begin{array}{l}\text { State of } \\
\text { alanine } \\
\text { amino- } \\
\text { transferase }\end{array}$} & \multirow[t]{2}{*}{ Histology } \\
\hline & & & $H B e A g$ & $A n t i-H B e$ & $\begin{array}{l}\text { Antibody to } \\
\delta \text { antigen }\end{array}$ & & \\
\hline 1 & $2 \cdot 5$ & $10 \cdot 5$ & - & + & + & $\uparrow \uparrow$ & \\
\hline 2 & 5 & $9 \cdot 5$ & + & - & + & $\uparrow \uparrow$ & Cirrhosis $(\delta+)$ \\
\hline 3 & $2 \cdot 5$ & 8 & - & + & + & $\uparrow \uparrow$ & \\
\hline 4 & 2 & 8 & + & - & - & $\uparrow \uparrow$ & \\
\hline 6 & 3 & 6 & - & + & - & $\uparrow \uparrow$ & Chronic active hepatitis \\
\hline 7 & 4 & $5 \cdot 5$ & - & + & - & $\uparrow$ & \\
\hline 8 & $7 \cdot 5$ & 2 & - & + & - & $\uparrow \uparrow$ & \\
\hline 9 & $5 \cdot 5$ & 2 & + & - & - & $\uparrow \uparrow$ & \\
\hline
\end{tabular}

$\mathrm{ND}=$ not determined.

*Before 1979 techniques other than radioimmunoassay, such as micro enzyme linked immunoadsorbent assay and reverse passive haemagglutination, were used to detect HBsAg.

+For state of alanine aminotransferase activity, $\uparrow \uparrow=$ persistent conspicuous rise, $\uparrow=$ transient mild rise

and in four others it was detected during the remainder of the period of observation. In eight children, antigenaemia was never detected, and only antibodies were repeatedly found in their sera samples. Besides the above mentioned three children, another patient developed overt acute hepatitis B during the follow up, while in the remaining 20 cases infection was not apparent. Seven children cleared HBsAg from the serum within six months, while the remaining nine developed a chronic carrier state. The characteristics of this subgroup are shown in Table 3. In seven children (cases 1-4, 6, 8, and 9) a rather severe chronic hepatitis developed, with a constant conspicuous rise in alanine aminotransferase values (from two up to nine times the upper normal limit) and hypergammaglobulinaemia in five of them (cases 1-3, 8, and 9). In the remaining two children chronic HBV infection seemed quite well tolerated, and the only evidence of the infection were transient mild rises of alanine aminotransferase activity (up to three times the upper normal limit).

At present only three children out of this group (cases 2, 4, and 9) still show a constant presence of $\mathrm{HBeAg}$ along with $\mathrm{HBsAg}$. Only case 6 has seroconverted from HBsAg to anti-HBs, after six years of chronic carriage; alanine and aspartate aminotransferase activities are at present mildly increased. Of course, concomitant non-A non-B hepatitis could be present and may partially account for the above mentioned findings, but, as no serologic tests are available at present for this diagnosis, no definite separation of the two entities can be made. Serological evidence of $\delta$ infection was found in the three children with the longest period of $\mathrm{HBsAg}$ positivity and severe liver disease (cases $1-3$ ); the lack of the finding of $\delta$ antigenaemia, of $\operatorname{IgM}$ antibody to $\delta$ antigen, or of a previous negative serologic result did not permit the detection of the moment of infection.
Liver biopsy examination was performed in two patients: chronic active hepatitis with initial cirrhosis was present in one case and chronic active hepatitis in the other. In accordance with serologic results, evidence of intrahepatic $\delta$ antigen was present only in case 2 . Finally, in no patient was $\alpha$ fetoprotein abnormal, and ultrasonographic examination gave no evidence of an intrahepatic space occupying mass.

\section{Discussion}

Hepatitis B virus infection has often been reported as a complication of replacement therapy in haemophilic patients. ${ }^{124-8}$ Factor concentrates, manufactured from plasma pools of multiple donors, in particular would expose patients to the risk of infection. A large review has recently shown, however, that the frequency of severe liver disease in patients receiving large pooled concentrates was no greater than in patients treated by cryoprecipitate. ${ }^{8}$ Besides, the use of factor VIII and IX concentrates, which are easy to handle, has permitted home infusion programmes and has resulted in a great improvement in the quality of life of haemophiliacs. ${ }^{13}$

As $\mathrm{HBV}$ infection is usually acquired during the first years of treatment most reports about adult haemophiliacs show a high prevalence of signs of past infection but cannot describe the characteristics and evolution of acute infection. Children do offer this opportunity. Our data show a high prevalence of $\mathrm{HBV}$ infection $(55 \%)$ in a paediatric group of haemophilic patients exposed early to treatment with concentrate. Comparable data about prevalence of infection (ranging from $44 \%^{4}$ to $63 \%^{14}$ ) have been previously described in paediatric groups; to account for a much higher reported percentage $(85 \%)^{5}$ the authors themselves ${ }^{1}{ }^{\text {suggested that }}$ 
group might have been exposed to treatment with concentrate before the HBsAg screening of plasma donors by sensitive tests. The higher prevalence of detectable HBsAg (present in $36 \%$ of the patients) in our group compared with other studies ${ }^{9}{ }^{10}$ might be the result of frequent screening done in our children, detecting even short lived antigenaemia. The patients described by Spero et al ${ }^{9}$ were older (up to 21 years) and it was likely that a high percentage had already seroconverted from HBsAg to anti-HBs. Furthermore, this might also account for the lower prevalence of HBsAg in haemophilic adult patients. ${ }^{3} 4$

A peculiar feature of our group was the very high incidence of chronic HBV infection, as nine out of 24 infected children $(38 \%)$ showed this behaviour. This high percentage seems to be halfway between the behaviour of normal children and of immunosuppressed ones, as in these two categories the rate of chronic evolution was reported to be $9 \%$ and $69 \%$, respectively. ${ }^{15}$

Multiple transfusions, with a continuous antigenic stimulation, could possibly lead to a derangement of the immune system and partially account for the impaired clearance of HBsAg in these patients.

As regards the age of infected children, Spero et al reported HBsAg chronicity in four out of seven haemophilic children who had been exposed to factor concentrates before 5 years of age compared with five out of 65 patients treated after 5 years of age. ${ }^{9}$ It was suggested then that the age of first exposure to factor concentrates might be an important element in the development of chronic liver disease and of chronic HBsAg carrier state. In our experience, however, the age of infection would seem to be a more important factor than the age of first exposure for predicting a chronic evolution: in fact, seven out of the 12 children infected before 5 years developed chronic HBV infection compared with two out of 12 patients infected after this age. The age at first exposure per se is not important, as all but two infected children had been first exposed to treatment with factor concentrate before 5 years; besides, no significant difference could be found in the age of first exposure between children with and without infection.

Haemophilic children seem to behave like nonhaemophilic ones, as it is known that the probability that HBV infection will lead to the carrier state is inversely related to the age of infection, and the risk of an infected child becoming a carrier drops rapidly during the first years of life. ${ }^{16}$

In our experience chronic infection seemed to be quite well tolerated on a clinical basis, but our partial,results, as well as others, ${ }^{6-8}$ indicate that only liver biopsy examination can assess the extent of hepatic involvement, owing to the lack of reliability of clinical and laboratory data.

Liver biopsy examination has been performed in haemophiliacs for years, ${ }^{6-8}$ as the appropriate substitution therapy makes it quite safe even in these patients. Even though no treatment is available for chronic hepatitis B infection up to now, it seems nevertheless important to assess the real liver involvement in these children to make a correct prognosis. Besides, a proper follow up can be started in the cases of cirrhosis, to detect complications of portal hypertension and to treat them early in the best way.

$\delta$ agent is a hepatitis agent that is defective and requires obligatory helper functions provided by HBV. ${ }^{11} \mathrm{~A}$ high prevalence of $\delta$ infection was shown in haemophilic patients infected by HBV, and the former agent occurred as a major cause of chronic liver disease. ${ }^{17}$ The three children with $\delta$ infection and severe liver disease we have described out of nine with chronic infection would confirm a poor prognosis in the presence of this coinfection; as four other children without ongoing $\delta$ infection showed rather severe liver disease, however, more data, with an accurate histologic diagnosis, are necessary to confirm this hypothesis and to assess the respective pathogenic roles of HBV and the $\delta$ agent.

Finally, in our experience, as in another, ${ }^{\prime}$ no evidence of neoplastic transformation was found; as the association, however, between HBV infection and hepatoma has already been reported in the paediatric age, ${ }^{18}$ a careful follow up of HBsAg positive patients is still mandatory. To prevent HBV infection (and an eventual $\delta$ superinfection) active immunisation against HBV seems to be the easiest solution at present. Besides, to reduce both hepatitis $B$ and non-A non-B hepatitis, treatment with hepatitis free clotting factor concentrates ${ }^{19}$ and the use (when possible) of volunteer donor cryoprecipitates are feasible choices.

The production of human factor VIII by recombinant DNA techniques should definitely solve the problem in the future. ${ }^{20}$

We thank Professor M Rizzetto and Dr C Lavarini, who kindly performed radioimmunoassays for antibody to $\partial$ antigen in serum samples, and Dr M Recchia for statistical analysis.

\section{References}

' Gerety RJ, Eyster ME. Hepatitis among hemophiliacs. In: Gerety RJ, ed. Non $A$ non $B$ hepatitis. New York: Academic Press, 1981:97-117.

2 Mannucci PM, Capitanio A. Del Ninno E, et al. Asymptomatic liver discase in hemophiliacs. J Clin Pathol 1975;28:620-4.

${ }^{3}$ Hasiba U, Eyster ME, Gill FM, et al. Liver dysfunction in Pennsylvania's multitransfused hemophiliacs. Dig Dis Sci $1980 ; 25: 776-82$. 
${ }^{4}$ Kim HC, Saidi P, Ackley AM, Bringelsen KA, Gocke DJ. Prevalence of type B and non-A, non-B hepatitis in hemophilia: relationship to chronic liver disease. Gastroenterology 1980; 79:1159-64.

5 Gerety RJ, Eyster ME, Tabor E, et al. Hepatitis B virus, hepatitis $A$ virus and persistently elevated aminotransferase in hemophiliacs. J Med Virol 1980;6:111-8.

' Lesesne HR. Morgan JE, Blatt PM, et al. Liver biopsy in hemophilia A. Ann Intern Med 1977;86:703-7.

${ }^{7}$ Mannucci PM, Ronchi G, Rota L, Colombo M. A clinicopathological study of liver disease in hemophiliacs. J Clin Path 1978:31:779-83.

* Aledort LM, Levine PH, Hilgartner M, et al. A study of liver biopsies and liver disease among hemophiliacs. Blood 1985;66:367-72.

9 Spero JA, Lewis JH, Fisher SE, Hasiba U, Van Thiel DH. The high risk of chronic liver disease in multitransfused juvenile hemophiliac patients. J Pediatr 1979;94:875-8.

10 Gomperts ED, Lazerson J, Berg D, Lockhart D, SergisDeavenport E. Hepatocellular enzyme patterns and hepatitis B virus exposure in multitransfused young and very young hemophilia patients. Am J Hematol 1981;11:55-9.

" Rizzetto M, Shih JW-K, Gerin JL. The hepatitis B virus associated delta antigen $(\delta)$ : isolation from liver, development of solid phase radioimmunoassays for delta and anti-delta and partial characterization of delta. J Immunol 1980;125:318-24.

12 De Groote J, Desmet VJ, Gedigk P, et al. A classification of chronic hepatitis. Lancet 1968;ii:626.
${ }^{13}$ Hilgartner MW. Current therapy. In: Hilgartner MW, ed. Hemophilia in children. Littleton, Mass: Publishing Sciences Group Inc [PSG], 1976:151-70.

${ }^{14}$ Scaroni C, Cancellieri V, Carnelli V. Moroni GA, Angeli M. Addition of hepatitis-B immunoglobulin to clotting factors. Lancet 1980;ii:537.

15 Bortolotti F, Cadrobbi P, Bertaggia A, Rude L, Alberti A, Realdi G. A 7 year survey of acute hepatitis type B. Arch Dis Child 1983;58:993-6.

16 Beasley RP, Hwang LY, Lin CC, et al. Incidence of hepatitis B virus infections in preschool children in Taiwan. $J$ Infect Dis 1982;146: 198-204.

17 Rizzetto M, Morello C, Mannucci PM, et al. Delta infection and liver disease in hemophilic carriers of hepatitis B surface antigen. J Infect Dis 1982;1:18-22.

18 Ohaki Y, Misugi K. Sasaki Y, Tsunoda A. Hepatitis B surface antigen positive hepatocellular carcinoma in children. Cancer 1983;51:822-8.

${ }^{19}$ Gerety R. Removal of hepatitis virus infectivity from clotting factor concentrates. Scand J Haematol /Suppl] 1984:33:309-12.

20) Brownlee GG, Rizza C. Clotting factor VIII cloned. Nature 1984;312:307.

Correspondence to Dr G Nebbia, Clinica Pediatrica I, dell Università degli Studi, Via Commenda 9, 20122 Milano, Italy.

Received 31 January 1986 